\title{
NEOLIBERALISMO Y ESCUELA. \\ TRANSFORMACIONES DE LA ESCUELA A PARTIR DE LAS POLÍTICAS NEOLIBERALES EN COLOMBIA*
}

\section{Neoliberalism and School. The Colombian School transformation by neoliberal politics}

Jorge Orlando Blanco Suárez**

Laura Duarte Romero***

Marcela Aragón Salazar****

Universidad Distrital Francisco José de Caldas. Bogotá D.C.

Recepción: 12 de mayo de 2017. Aprobación: 22 de septiembre de 2017.

DOI: http://dx.doi.org/10.21017/Rev.Repub.2017.v23.a32

\section{RESUMEN}

El presente texto analiza las transformaciones de las escuelas colombianas generadas por las políticas educativas de orientación neoliberal que en esta se han implementado desde finales de los años ochenta hasta la actualidad. Intenta precisar las implicaciones de estas políticas en términos de afectación de los sentidos de la educación y de sus implicaciones para las prácticas educativas en general. Frente a las imposturas neoliberales y desde una actitud pedagógica crítica, el documento plantea la necesidad de re-politizar la escuela, rescatar el sentido de la política y hacer de este espacio un escenario de formación de sujetos políticos. El problema central de investigación es comprender cómo se han impulsado políticas neoliberales en las escuelas colombianas y cómo estas han re-configurado la formación escolar a la producción de sujetos adaptados a los mandatos del mercado.

* Artículo de reflexión, producto del proyecto pedagógico-investigativo titulado: Socialización y formación política en instituciones educativas en Bogotá, dirigido por los profesores Iván Roa y Jorge Orlando Blanco.

** Docente-Investigador, Universidad Distrital Francisco José de Caldas. Coordinador de la Licenciatura en Ciencias Sociales. Candidato a Doctor en Ciencias Sociales con Especialización en Estudios Andinos por la FLACSO-Ecuador. Miembro del Grupo de Investigación Amauta, Pedagogías Críticas y Formación de Sujetos.

*** Estudiante investigadora vinculada al programa de Licenciatura en Educación Básica con Énfasis en Ciencias Sociales de la Universidad Distrital Francisco José de Caldas.

****Estudiante investigadora vinculada al programa de Licenciatura en Educación Básica con Énfasis en Ciencias Sociales de la Universidad Distrital Francisco José de Caldas. 
Palabras clave: escuela, neoliberalismo, sujeto neoliberal, sujeto político, socialización política, pedagogía crítica.

\begin{abstract}
The paper analyze the Colombian school transformations generated by the neoliberal educational politics from eighties to today. By doing so, try to understand the sense of education that the neoliberal logic have imposed in Colombian schools and its impact in the relations between the scholars actors: teachers, students, managers, and others. The point of view in a sociological debate over the impacts of structural/institutional reforms in the daily live. Against the neoliberal impostures, the paper defends the idea of a school as scenario for the politics education, critical deliberation and the construction of a political subjectivity. As research question, we try to understand the effects of Neoliberal educations politics inside the daily life.
\end{abstract}

Key words: school, neoliberalism, neoliberal subject, political subject, political socialization.

\title{
INTRODUCCIÓN
}

Desde hace aproximadamente tres décadas, se puede evidenciar que el sistema escolar colombiano en todos sus niveles está cada vez más influenciado por las lógicas y políticas neoliberales. El discurso neoliberal ha puesto a la escolarización como elemento central para el crecimiento económico y la movilidad social (Mészáros, 2008) y se han propiciado las políticas y reformas necesarias para el logro de dichos objetivos, como también para perpetuar la estructura social neoliberal dominante.

En América Latina y el Caribe específicamente, se introducen proyectos de reformas educativas en respuesta a la crisis económica y política de la década de los ochenta. A partir de la aceptación de esta alternativa ideológica, por parte de los gobiernos y, progresivamente por parte de otros actores sociales, se viene legitimando una influencia creciente de los agentes y lógicas del mercado en los sistemas educativos (Puigross, 1996). Esto ha implicado que las instituciones escolares hayan sido y continúen siendo reformadas en sus políticas y limitadas en su autonomía. Las presiones sobre sus estructuras financieras, sus procedimientos, sus orientaciones curriculares, sus procesos formativos, evaluativos y de enseñanza, han estado orientadas a fortalecer la idea de que los sistemas educativos funcionan (o deberían funcionar), como mercados en los cuales los sujetos buscan (o deberían buscar) la cualificación de sus habilidades instrumentales, productivas y no su formación integral. La educación, 
desde esta lógica, se ve más como una inversión individual y no como un derecho y bien colectivo.

Dichas reformas educacionales se expresan tanto en el currículo, como en las normativas institucionales y en la cotidianidad de los actores partícipes. Esto genera, por un lado, que la escuela se erosione como espacio de socialización y construcción de sentidos colectivos de lo público, pues la oferta de alternativas concretas de integración social y posibilidades diversas de estilos de vida, se reduce a la producción de productores/consumidores; a la formación para el trabajo o para el éxito académico-económico. De esta manera, se favorece la manipulación de las personalidades por factores como el consumo y el mercado, lo que deriva en sujetos anclados en la defensa de lo propio y la negación constante del otro (McLaren, 1997). En términos de Mirés (1998), podríamos decir que las escuelas contemporáneas, lejos de contribuir a fortalecer los procesos de socialización, vienen contribuyendo a todo lo contrario: la des-socialización. Así, la escuela, lejos de favorecer el desarrollo del pensamiento crítico frente al orden ideológico y económico dominante, ha estado presionada a convertirse en una "máquina" de producción de sujetos "muy bien integrados", a la desintegración generalizada, al combate del todos contra todos, bajo el influjo de la "mano invisible" del mercado. Sin embargo, existen procesos que le apuestan a la construcción de una escuela como espacio que forma sujetos y construye subjetividades políticas y sociales; que propende por la constitución de una escuela que forme sujetos críticos, emancipados, reflexivos y propositivos. Específicamente, esta investigación busca comprender cómo las políticas educativas derivadas del neoliberalismo han generado transformaciones en la escuela y cómo desde estas trasformaciones se ha buscado impactar la construcción de las subjetividades escolares.

Para el desarrollo de este propósito el texto se divide en tres partes. En la primera se expone la concepción neoliberal de la educación y cómo a partir de esta se impulsa la configuración de una sociedad neoliberal. En este mismo apartado, se realiza un balance de la manera en que las políticas neoliberales se han impulsado en el campo educativo colombiano. Finalizando se presenta un esbozo del sujeto que se forma en las escuelas contemporáneas a partir de estas reformas y cómo afectan a las comunidades educativas en su totalidad. En la segunda parte, desde la sociología de la educación, se analizan los procesos de (des)socialización en una sociedad configurada por el neoliberalismo y además, cómo este contribuye a formar un determinado tipo de sujeto y de sociedad. En un tercer apartado, se propone, desde la noción de formación política, la necesidad de apostar por la reconfiguración del sujeto neoliberal que están formando las escuelas colombianas, así como de repotenciar la construcción de subjetividades políticas desde una postura crítica de la pedagogía y del sistema escolar. 


\section{ESTRATEGIA METODOLÓGICA}

Para dar respuesta al problema de investigación planteado, se buscó, en primer lugar, comprender las lógicas neoliberales y el sentido y función que desde éstas se le ha dado a las escuelas en las sociedades contemporáneas. Esta comprensión derivó en el análisis crítico de los postulados de los más connotados defensores de la economía de "libre mercado" y de la manera en que estos han planteado el lugar de la educación como instrumento de la reproducción del capital y de los procesos de acumulación capitalista en general. Una vez se comprenden críticamente estos postulados, se pasa a identificar e interpretar la manera en que, desde la concepción neoliberal hegemónica de la educación y de la escuela, se han generado transformaciones institucionales en el sistema educativo colombiano, con el fin de imponer un proyecto instrumental de la escuela. Se encuentra allí que los discursos sobre el emprendedurismo, la competencia, la competitividad y eficiencia, han marcado las reformas de este sistema educativo, reduciendo la función escolar (particularmente de la escuela orientada a los sectores populares y de clases medias) a la producción de mano de obra cualificada y sumisa a los mandatos del capital. No obstante esta pretensión, se asume a la escuela como un campo de disputa, de lucha por la hegemonía cultural y política en la que los actores escolares no son sumisos, sino que se produce un combate permanente entre los mismos.

De acuerdo a lo anterior, si bien el objetivo de esta investigación trata de analizar las bases de una estructura institucional edificada por lógicas neoliberales de mercado y consumo, también se busca deconstruir dicha estructura, precisamente develando el carácter de impostura ideológica del discurso neoliberal. Desde una lectura crítica de estos procesos de transformación del sistema escolar colombiano, se proponen alternativas pedagógicas para lograr la transformación de la misma. El análisis se realizó a partir de la técnica de investigación documental, en la que se hizo un rastreo de documentos oficiales -leyes, reformas y decretos- en materia de educación, expedidos por el Gobierno Nacional y entidades estatales desde comienzos de la década de los noventa hasta hoy. Finalmente, la reflexión se apoyó en investigaciones realizadas en América Latina y en Colombia en particular sobre los procesos de imposición del neoliberalismo en los sistemas escolares.

\section{RESULTADOS}

\section{La educación en el Neoliberalismo}

Luego de más de treinta años de neoliberalismo, este ha logrado, para algunos, constituirse en "sentido común", en doxa (McLaren, 2015: 53). Tal como lo 
planteó Margareth Tatcher en su proclama del There is not alternative (Blanco, 2004), la doctrina neoliberal ha logrado ser aceptada por buena parte de los gobiernos del mundo. En América Latina, luego de la crisis del desarrollismo, este se estableció como modelo dominante y se ha desplegado en distintas esferas de la vida social.

En el campo educativo, Carlos Miñana y José Rodríguez (2002), igual que Perry Anderson (2003), consideran muy importante la influencia de la obra de Hayek, The constitution of Liberty (1960). Para estos autores, a grandes rasgos, la educación para Hayek, estaría orientada a la adquisición de técnicas, valores y conocimientos básicos para un mejor desempeño en el campo económico. Los sujetos se forman para competir mejor y la libre competencia se establece como un bien supremo que los estados y las sociedades en su conjunto deben asegurar a toda costa. Para Hayek, comentan Miñana y Rodríguez (2002), la educación debe estar ligada a la noción de "libertad" y, por tanto, estar por fuera del campo de acción del Estado. De este modo, el Estado solo podría financiar una instrucción básica obligatoria (un mal menor para Hayek) y dejar a las fuerzas del mercado la oferta de "servicios educativos". En los otros niveles de educación, "...los individuos son libres de escoger lo que más les interese" (Miñana y Rodríguez, 2002: 4). Para Miñana y Rodríguez, estos planteamientos estarían en coherencia con los de otro de los "padres del neoliberalismo", como Milton Friedman quien consideraba que si había que financiar la educación, únicamente podría hacerse por la vía de la demanda, a través de bonos, vales y cheques o vouchers.

En ésta misma dirección, para Estrada (2010), dentro de una economía neoliberal, lo que interesa es "sufragar el coste de la instrucción a cargo de los ingresos públicos, sin mantener escuelas estatales, solo con facilitar a los padres de familia con bonos que, cubriendo el importe de los gastos que implicara la educación de cada adolescente, pudieran ser entregados a los establecimientos educativos de su elección" (Hayek, citado por Estrada, 2010: 18)

«En esta perspectiva, la instrucción pública estaría en los primeros años de formación. La siguiente sería una educación privada orientada por las lógicas del mercado, pues de ésta manera la misma estaría libre de una ideología impuesta por un Estado 'paternalista' y 'autoritario». En suma, Miñana y Rodríguez consideran que la educación desde una perspectiva neoliberal se caracterizaría por: 1 . La búsqueda de fortalecer la libre competencia; 2 . Las universidades y escuelas deben pensarse como empresas prestadoras de servicios educativos; 3 . Hay que eliminar derechos no vinculados a la competitividad y estimular la productividad; 4 . La flexibilización del mercado laboral en el campo educativo; 5 . Realizar pruebas y calificaciones estándar periódicamente; 6 . El impulso de una política de créditos educativos para 
financiar a la demanda y; 7 . La producción de conocimiento como una industria (Miñana y Rodríguez, 2002:8)

La influencia de ver la educación de esta manera, habría comenzado a sentirse a partir de la década de los ochenta. Para Christian Laval (2004), la escuela neoliberal inicia a partir de esta década, cuando el discurso de la competencia donde prima el individualismo-, la productividad -asociada la calidad del trabajo- y la flexibilidad- una cualidad del estudiante y trabajador-, comienzan a constituirse en los ejes vertebradores del discurso neoliberal sobre la educación. En este discurso, dice Laval: "los únicos valores legítimos son la eficacia productiva, la movilidad intelectual, mental y afectiva, y el éxito personal" (Laval, 2004: 15). De esta manera lo que se busca, y en buena medida se ha logrado, es la creación de un sujeto auto-disciplinado y flexible, que se mueve en la búsqueda de cualificación y certificación constante de habilidades.

\section{Educación neoliberal en América Latina}

De acuerdo a lo anterior, es desde estas formas de entender la educación que se han venido reconfigurando los sistemas escolares en América Latina. Este modelo propone que para alcanzar el desarrollo estándar y procurar el funcionamiento del sistema capitalista en su reestructuración, la escuela debía estar vinculada directamente con la economía y el mercado de trabajo; producir masivamente mano de obra, preparar a la infancia para su posicionamiento y distribución en la estructura de división del trabajo y promover el ideal de progreso y movilidad social individual. En este sentido, se argumenta que los grandes sistemas escolares (administrados y orientados por los actores estatales) son ineficientes y de baja calidad. Por tal motivo, la participación del Estado en la financiación de la educación debía reducirse y fortalecer la participación de actores privados. Para Puigross "La nueva conducción de la educación latinoamericana estaba ya definida; los sujetos determinantes de la política académica y curricular eran directamente las fuerzas económicas" (Puigross, 1996: 7). Eran estas fuerzas, las únicas capaces de introducir en el campo de la producción económica, como en el de la educación específicamente, las mejoras necesarias para lograr mayores niveles de calidad, productividad, competitividad y eficiencia. Se buscó entonces fortalecer programas de ampliación de cobertura educativa en los distintos niveles, así como se profundizó la campaña sobre el necesario mejoramiento de la calidad educativa. No obstante, como lo plantea Renán Vega Cantor:

Cuando se abusa tanto de un vocablo como el de calidad de la educación se imponen una serie de trampas terminológicas, intrínsecas y extrínsecas, cuya finalidad radica en presentar unas determinadas politicas y decisiones educativas como si fueran naturales, un resultado de fuerzas irreversibles, ligadas al 
mercado, un eufemismo para no nombrar al capitalismo. En ese sentido, la calidad educativa aparece como un término normal, indiscutible y que todos debemos aceptar. Sin embargo, si se examina con cuidado, lo que se imponen son unas trampas ideológicas, unas seudo verdades de sentido común, que no resisten el más mínimo análisis" (Vega: 2012). ${ }^{1}$

\section{Reformas educativas en la Colombia neoliberal}

Colombia no ha sido ajena a la influencia del neoliberalismo en el campo educativo. Las políticas neoliberales, aunque se fueron implementando gradualmente en los años ochenta, o incluso, desde los años setenta, se consolidan a comienzos de los noventa, durante el mandato de César Gaviria. En este gobierno, se habría configurado como "punto de inflexión en la tarea de construcción del orden neoliberal en Colombia" (Estrada, 2004: 71).

Es así como en este gobierno se diseñan, formulan e implementan reformas, leyes y decretos en materia de mercados laboral, de capitales y de bienes y servicios, y se introduce el discurso de la calidad con más fuerza (Lizarazo, 2008). En este último ingresan la salud y la educación, ya no como derechos, sino como servicios sometidos a las dinámicas de la oferta y la demanda. Así pues, se generan reformas legales y el marco de la Constitución de 1991 va a servir de escenario para la profundización de las políticas neoliberales en materia educativa. Durante el gobierno de Gaviria, por ejemplo, junto a la "apertura económica", se produce el "Plan de Apertura Educativa", que buscaba disminuir los niveles de deserción y repetición, considerados alarmantes y se busca con esto mejorar la calidad de la educación (Miñana y Rodríguez, 2002; Sánchez, 2015). Es precisamente a partir del gobierno del presidente Cesar Gaviria Trujillo (1990-1994) que las políticas neoliberales y las reformas de mercado se van entronizar para orientar el rediseño institucional del país respecto a los requerimientos de la apertura económica y el mercado globalizado. En ese contexto en los siguientes gobiernos, de Ernesto Samper Pizano (19941998), Andrés Pastrana Arango (1998-2002), Álvaro Uribe Vélez (2002-2010), los planes sectoriales y las respectivas políticas públicas mostrarán continuidad

1 Para otras visiones críticas sobre la manera en que el discurso de la calidad se ha impuesto en las políticas educativas en Colombia, puede verse también, Arias, 2009. El autor muestra cómo esta imposición ha sido el resultado de la presión de los organismos multilaterales y la lucha de los poderes por determinar el destino de la educación. Igualmente se puede consultar el texto del profesor Alfonso Tamayo que da cuenta ya no de una perspectiva teórica crítica sobre el discurso de la calidad, sino sobre la manera en que el denominado Movimiento Pedagógico Nacional, desde los años ochenta y comienzos de los noventa, planteó alternativas a lo que venía edificándose como el discurso dominante. Ver al respecto Tamayo, 2006. 
y articulación efectiva con las políticas de ajuste estructural y modernización neoliberal (Bocanegra, 2006, p. 45).

La Constitución Política de 1991 que en términos de la formalidad jurídica inaugura el Estado Social de Derecho en Colombia, en términos de la realidad social que el país afrontaba en su momento, marca el arranque del acondicionamiento de su estructura jurídico política a los requerimientos del proceso de apertura y liberalización económica, con todo lo que esto implicó en materias de derechos, garantías y libertades para los ciudadanos (Bocanegra, 2006, pp. 43-44).

Desde la Constitución de 1991 (artículo 67), se establece la educación como un derecho ciudadano y prioridad del gobierno. Por su parte la Ley 115 de 1994 (Ley General de Educación) establece que todos los colombianos tienen derecho a acceder a la educación para su desarrollo personal y para el beneficio de la sociedad (OCDE y MEN, 2015). También se produce la Ley 30 de 1992, por la cual se organiza el servicio público de Educación Superior, que "(...) establece que la educación superior es un servicio público que puede ser ofrecido tanto por instituciones públicas como privadas. Bajo esta lógica se reafirma un sistema mixto de financiamiento de la educación superior, aunque, como se verá, favorecería a las universidades privadas más que a las públicas." (Blanco, 2014: 143).

Estas dos grandes leyes se han ido reformando desde su reglamentación hasta hoy, incorporando progresivamente los postulados del neoliberalismo: la libre competencia, la flexibilización, el emprendimiento, la privatización, la libertad -concebida desde una mirada neoliberal, como libertad económica o libertad de los actores económicos-, la eficiencia, la innovación, etc.

De la misma manera que en América Latina, en Colombia:

"las políticas implementadas por los gobiernos para mejorar la calidad de la educación fueron y todavía son, entre otras, las siguientes: más horas y más días de clases, jornada extendida o escolar completa, descentralización, impulso a la privatización, financiamiento compartido, privatización con financiamiento estatal, evaluación nacional e internacional (mucha evaluación estandarizada y centralizada), foco en los directores y su gestión, ranking y competencia entre escuelas" (IEAL, 2015).

En el caso de la evaluación en Colombia, como factor de gran relevancia para analizar los procesos educativos, sus debilidades, y hasta para comparar la calidad y eficiencia de los sistemas educativos entre países o al interior de los países, se han impulsado distintas concepciones. Desde la misma Ley General de Educación, se establecen y se fijan artículos en torno a su concepción, 
funcionalidad, organización, y se les agrega el indicador de la calidad -característico en la educación neoliberal-. Según Sánchez (2015) la evaluación se instituye como:

exigencia y obligación (Art. 4), estrategia de participación (Art. 6), instrumento para obtención de estímulos (Art. 73), mecanismo de Acreditación e Información (Art. 75), criterio regulador de currículos, programas y planes de estudio (Arts. 78-79), dispositivo de mejoramiento de la calidad de la educación, instrumento sancionatorio de instituciones (Art. 80), aparato sancionatorio de sujetos: docentes, directivos docentes sector privado y estatales (Arts. 81,82,83, derogado por el artículo 113 de la Ley 715 de 2001), aparato indicador de gestión, engranaje de regulación institucional (Art. 84), instancia indicativa de permanencia o exclusión (Art. 96), mecanismo de certificación y/o promoción (Art. 97), elemento jerarquizador (Art. 90), dispositivo sancionatorio de poder y control (Art. 132), instrumento de agenciamiento (Art. 144), política y planeación, inspección y vigilancia, administración, normativas (Art. 151), entre otras facultades. (Sánchez, 2015: 100-103).

Estas formas de asumir el problema de la evaluación de/en los sistemas educativos, da cuenta de la importancia que la misma cobra como "instrumento" de medición de los resultados, sea para "sancionar" o "premiar" a los sujetos y a las instituciones. Aquellos y estas han sido sometidos, de manera cada vez más frecuente e intensa a distintos sistemas de evaluación y medición de sus resultados, ganando cada vez más relevancia actores económicos privados nacionales y extranjeros en estos procesos. En la misma dirección se encuentran los exámenes estandarizados, regulados por el Instituto Colombiano para la Evaluación de la Educación (ICFES) que se realizan en todos los niveles de la educación básica y media, incluso en la educación superior. Por otro lado, Colombia se ha vinculado también, como país asociado en las pruebas internacionales PISA (Programa para la Evaluación de Alumnos de la OCDE) (IEAL, 2015). En buena medida, puede decirse que el incremento en las evaluaciones a las instituciones y a los sujetos se convierte en un mecanismo regulador de conductas y comportamientos, así como instrumento de medición y sanción/ premio de la gestión y gerencia educativa.

De acuerdo con lo anterior, la evaluación es un mecanismo que media entre las interacciones que se producen a nivel escolar, y se edifica como un factor imprescindible en la formación de sujetos e instituciones. Como se puede evidenciar en la reflexión de Sánchez (2015), dado que la evaluación se da en varios niveles del sistema educativo, se generan competencia y jerarquías, conflictividades y tensiones no solo entre estudiantes, sino entre estudiantes y profesores, profesores y directivas, directivas y otros estamentos institucionales, 
que regulan la educación. La competencia por mostrar resultados, además ha configurado unas lógicas y prácticas de medición de los "mejores colegios" e instituciones escolares que lejos de contribuir a la igualdad o la equidad en el sistema educativo, han profundizado la desigualdad ${ }^{2}$.

Sumado a lo anterior se han implementado reformas normativas que reglamentan los distintos niveles de la educación, como el Decreto 230 de 2002, que regulaba la evaluación interna y promovía la promoción automática de los estudiantes, con criterios más económicos que pedagógicos o didácticos (Lizarazo, 2008). Así mismo, se encuentra el Decreto 272 de 1998 en materia de evaluación y acreditación a IES, que incorpora procesos de "auto-evaluación" de las instituciones de educación superior y ha favorecido la competencia mercantil, entre instituciones de educación superior (Blanco, 2014), llevándolas a actuar bajo orientaciones de entidades económicas privadas, nacionales e internacionales (Sánchez, 2013).

Por otro lado, como señala Estrada (2003), desde gobiernos como el de Álvaro Uribe en el programa "Revolución Educativa" se promueve la mercantilización de la educación a través del Acuerdo General sobre Libre Comercio (GATS), donde se encuentran los "servicios de educación" y en el que se promueven las inversiones extranjeras, la apertura a los mercados, la competencia y la educación sin fronteras. En la misma dirección, se halla un convenio que, aunque no es nacional, sí tiene una amplia incidencia en Bogotá; el Convenio 001 de 2005 entre el SENA (Servicio Nacional de Aprendizaje) y la SED (Secretaría de Educación Distrital) que articula la educación media pública con la educación para el trabajo y donde se promueve el fortalecimiento de la educación técnica para las clases más bajas. (SENA-Alcaldía Mayor de Bogotá,

2 La revista Dinero, desde el año 2000 publica anualmente el listado de los mejores colegios de Colombia, basada en los resultados de pruebas Saber 11 (conocidas antes como exámenes del ICFES). El inicio de estas publicaciones fue visto por la revista como una información muy importante para padres de familia y estudiantes, pues contribuía a mejorar los criterios de elección (Dinero, 2000). En los listados de esta revista, la presencia de colegios públicos ha sido marginal. En el año 2011, los resultados de la implementación de políticas de calidad y de evaluación de instituciones no era el más alentador en términos de igualdad. De hecho, autores como Villegas y López (2001), mostraban cómo lo que se estaba produciendo era un incremento de la desigualdad entre los resultados de la mayor parte de las instituciones públicas frente a las privadas de clases medias-altas y altas. De hecho, los autores afirman que lo que venía edificándose en Colombia era un "apartheid educativo", una mayor segregación entre clases sociales. La evaluación constante ha llegado a constituirse en una práctica escolar naturalizada, a través del establecimiento del "día de la excelencia educativa" o "Día E", que sirve para clasificar también a los "mejores colegios del país", los "martes de prueba"; el establecimiento del Índice Sintético de Calidad Educativa, entre otras medidas. 
SED, 2005), cuyos resultados han sido cuestionados por promover la formación en campos de baja cualificación, que reproducen estructuras desiguales de acceso a recursos y bienestar (Díaz y Celis, 2010; García y Quiroz, 2011 ).

Con relación a la anterior, en el 2006 se crea Ley 1014 "De fomento a la cultura del emprendimiento", que promueve la formación de un "espíritu laboral" y de empresa y además establece una cátedra obligatoria en establecimientos públicos y privados y en todos los niveles de la educación, denominada "Cátedra de emprendimiento" (Ley 1014, 2006). Más adelante, se implementará el Decreto 2355 de 2009, que promueve la privatización de la educación pública y que Estrada (2010) explica como un decreto que:

\section{(...) reglamenta la contratación del servicio público educativo por parte de las entidades territoriales certificadas (...) y al abrirse a la educación contratada, la decisión política del Estado consiste en debilitar estratégicamente la educa- ción pública por cuanto las insuficiencias y limitaciones de esta, en lugar de resolverse por la vía de su fortalecimiento., se enfrentan más bien recurriendo a terceros, a contratistas (Estrada, 2010: 20).}

En cuanto la financiación de la educación, Colombia en la actualidad destina un $6.7 \%$ del PIB para el gasto público educativo. Sin embargo, el gasto por estudiante está muy por debajo del promedio de la OCDE y de otras economías emergentes en América Latina. Esto aplica para todos los niveles, pero en particular, para la educación media y la educación superior (OCDE, 2016, p. 50). Por otra parte, se han establecido mecanismos institucionales para regular la financiación de la demanda educativa como el ICETEX, que funciona desde mediados de siglo, pero que hoy ha cobrado mayor relevancia al ser quien financia el 20\% de la educación superior en Colombia (OCDE, 2016: 275).

Reformas más recientes se pueden ubicar en el año 2011 con el proyecto de Reforma a la Ley 30 -que fracasó-, o en el Decreto 2034 de 2014 o el "Acuerdo por lo superior". Hoy, proyectos de gran peso como el Programa Ser Pilo Paga que se lanzó en el 2014 como una estrategia para aumentar la cobertura de la educación superior de 40.000 jóvenes (10.000 por año, cifra que ha ido aumentando de manera insignificante) de los sectores sociales menos favorecidos -en los estratos 1, 2 y 3- financiando el costo de las matrículas y algunos costos de sostenimiento, donde la selección de los estudiantes se hace a partir de su desempeño en las pruebas Saber 11 y a partir de la evaluación de sus condiciones socioeconómicas ${ }^{3}$. Por otro lado, el programa se implementó

3 La idea de este programa era insertar un pequeño cambio en el sistema para alterar todo el sistema. De lo que se trataba era de establecer un mecanismo que permitiera a los 
como un ejercicio de proyección para actuar durante 4 años; no obstante, existe el Proyecto de Ley 258 de 2016 (Congreso de Colombia, 2016) que busca que se eleve a política de Estado. Programas como este fomentan la privatización y mercantilización de la educación superior, pero también entronizan la evaluación estandarizada como un mecanismo que define quienes son "pilos" y quienes no, quiénes pueden acceder a la educación superior y quiénes no. Además, de suscitar la competencia entre los estudiantes y a aumentar las brechas de desigualdad pues solo un ínfimo porcentaje puede acceder a él.

Por otro lado, para Carlos Miñana, la política educativa colombiana se ha construido en torno a tres ejes referenciales: equidad, eficiencia y calidad. Ejes que han reforzado, pese a que contemplan la idea de la "equidad", el modelo de competencia, ganando centralización, control y legitimidad, y:

\begin{abstract}
Al mismo tiempo, sin perder el control, con las pruebas estandarizadas, con la evaluación a docentes, con los parámetros e indicadores de gestión, con los sistemas de información, se ha mostrado (la educación) como una máquina aplanadora de la diferencia, ha hecho iguales a los niños, a los y las docentes, a las instituciones educativas, a las secretarías de educación para, una vez convertidos en seres capaces de competir, una vez legitimado el fair playing, expandir el mercado educativo (Miñana, 2010, p. 47).
\end{abstract}

\footnotetext{
"mejores estudiantes" de los estratos más bajos, acceder a la educación superior (El Espectador, 6-12-2015). La candidez con la que uno de los gestores de "ser pilo paga" (que en buena medida lo que hace es establecer un sistema de vouchers, por el que compiten las instituciones privadas, fundamentalmente) presenta su iniciativa es una muestra muy clara, de la manera en que, desde ciertos sectores sociales académicos, asumen que la financiación de la educación debe hacerse fortaleciendo la demanda y no la oferta. Esta lógica se ha establecido como sentido común. Se da por hecho que la financiación es limitada y que la manera más eficiente de financiar a los más pobres es a través de una lógica liberal en la que estos, guiados por sus propios criterios de racionalidad, puedan elegir la universidad que más se adapte a sus expectativas de avance social y progreso académico-económico. La desigualdad en el acceso a los recursos por parte de entidades públicas y privadas ha sido evidente. La mayor parte de estos ha ido a instituciones privadas, que han llegado a recibir hasta el $98 \%$ de los recursos destinados a ser pilo paga (Semana, 28-06-2016). Además de esto, el número de estudiantes "beneficiados" por el programa, resulta ser muy limitado ya que según el ICFES de casi 482.000 estudiantes de estratos 1, 2 y 3 que se gradúan cada año, menos del $10 \%$ podría acceder al mismo, y la mayoría de quienes acceden a este, ingresan a universidades privadas, dinero que se podría invertir en una educación pública y de calidad pues, los costos por estudiante varían en más de un $50 \%$ de la universidad privada a la pública (El espectador, 2016).
} 
En este contexto, la educación configurada así, ha quedado relegada a la simple construcción de estrategias para el fortalecimiento del mercado, puesta al servicio de la administración de turno e incrementando los indicadores sin solucionar de fondo los problemas escolares (aumentando la cobertura sin incrementar el gasto educativo, es decir, más estudiantes por docente e incrementando las tensiones al interior de las instituciones escolares). Como si todo lo anterior no fuera suficiente, la crisis en la educación se ha profundizado debido a altos niveles corrupción, clientelismo y exclusión en el sector educativo y a las aberrantes condiciones de desigualdad, los prejuicios y la segregación de amplios sectores sociales.

\section{El sujeto neoliberal}

Hasta acá se ha querido evidenciar cómo la sociedad contemporánea y, específicamente la realidad de nuestro sistema educativo, se ha visto afectada y configurada por el modelo neoliberal. Es en este punto donde cabe resaltar que estos factores no solo se perciben en las estructuras objetivas de la realidad, sino también en la subjetividad de las estructuras mentales, como diría Bourdieu (1997).

Es evidente que hasta en las estructuras subjetivas de las conciencias de cada sujeto, y en las interacciones cotidianas, el egoísmo o egocentrismo se manifiesta cada vez más. Al implantarse este modelo en la década de los ochenta y consolidarse en los noventa nadie parece escapar de él. Este ha contribuido a la mercantilización de la vida humana, al extremo de elaborar, sin desafío alguno, los esquemas mentales de los sujetos, quienes son reducidos a ser Homo economicus (McLaren, 2015).

Lo que hace que el funcionamiento del sistema capitalista se perpetúe es que los sujetos obedezcan de forma consciente o inconsciente a estas lógicas. El objetivo fundamental del modelo neoliberal como reestructuración del capitalismo mundial es el desarrollo y el crecimiento económico, y que por lo tanto, su demanda es que los sujetos sean formados para el trabajo, que es el aspecto de la vida social que más se vincula con el desarrollo económico de los países, esto es, en términos de McLaren (2015) que impone una jerarquía del capital y de los medios de obtención de este, y conduce al trabajo y al trabajador, a una cadena de consumo-obsolescencia-consumo.

Teniendo en cuenta la imposición de valores, códigos y leyes, que la estructura social agenciada desde el neoliberalismo, hace sobre el sujeto, es posible deducir que el ser humano es presionado a realizar acciones cuyo control está por encima de su voluntad, que actúa sin previsión a fines pues se debe adaptar a situaciones para las que no siempre está preparado ya sea por condiciones 
económicas, físicas o sociales. Es así como el sujeto neoliberal es producido y re-absorbido permanentemente, por el sistema imperante y queda desprovisto de una identidad que lo encamine hacia la reflexión y la autonomía. Por el contrario, el sujeto llega a la apatía y al conformismo y a una despersonalización casi total. A esto le llama Mires (2005) apoyado en perspectivas psicoanalíticas y sociológicas, la caída en el narcisismo, ya no como una patología individual, sino social.

En este sentido se puede argumentar, que el yo se convierte en objeto de sí mismo al no poder integrarse a la sociedad de forma plena; es decir, de forma normal a las estructuras sociales, producto de una "fallida comunicación entre ese Yo y los objetos que ha interiorizado y/o lo rodean" (Mires, 2005, p. 200). Esto, debido a dificultades que se adquieren en el desarrollo cultural del sujeto, que son generadas por el Estado y la estructura social en general. Chul-Han (2014) propone la noción de autoexplotación ejercida por el sujeto neoliberal, argumentando que el neoliberalismo explota la libertad de los sujetos, porque produce el deseo y el ideal de tránsito de una vida a otra entre -como se expone anteriormente- un presente de sacrificio, pero un futuro, sin precisar, de bienestar. Esto, dentro de la sociedad neoliberal, implica el alcance del progreso material y la posibilidad de movilidad social.

En esta fase del capitalismo se promete la libertad individual y la libre competencia de mercado descansa en esta noción. Siguiendo a Chul-Han (2014) el poder hacer genera más dependencia y coacciona más al sujeto que el deber hacer, pues es desde el poder hacer -o poder alcanzar- (con el incremento de la capacidad de consumo) que se intenta crear sujetos individualistas, más que subjetividades. Visiones propias del darwinismo social pueden entrar a dialogar en esta forma de entender la vida humana, pues es desde la idea del progreso material y el esfuerzo individual, que el sujeto creado por el neoliberalismo encuentra plena realización. Hace que él mismo se explote sin reconocer que, en realidad, está siendo explotado externamente. El está pensando en sí mismo, y sus propias necesidades, lo que no quiere decir que el mismo sistema y las brechas de desigualdad no lo fuercen a hacerlo. No obstante, lo hace por ambición o por necesidad ya que, tal como fue planteado por Deleuze y Guattari, "no es el deseo el que se apoya sobre las necesidades, sino al contrario, son las necesidades las que se derivan del deseo: son contraproductos en lo real que el deseo produce" (Deleuze y Guattari, 1973, p. 33). Así pues, el sujeto neoliberal desea desde la producción deseante el lujo, el poder y el dinero (Mires 2005), “bienes" cuyo acceso es cada vez más desigual.

De este modo, lo que fue visto en la crítica psicoanalítica a los efectos perversos de las sociedades capitalistas, se materializa en las sociedades contemporáneas neoliberales. En medio de la expansión fascista, Erich Fromm, 
mostraba la profundidad del poder de lo económico en la determinación de la subjetividad:

Así el modo de vida, tal como se halla predeterminado para el individuo por obra de las características peculiares de un sistema económico, llega a ser el factor primordial en la determinación de toda la estructura de su carácter, por cuanto la imperiosa necesidad de auto-conservación lo obliga a aceptar las condiciones en las cuales debe vivir (Fromm, 1941: 44).

Es desde este lugar, que lo que el individualismo contemporáneo configura sea una pérdida progresiva de la individualidad e identidad de los sujetos. El individualismo, entendido como el "proceso de pérdida de identidad, recogimiento de sí mismo por incomunicación con los demás, cae en la masificación. Favorece a la manipulación de la personalidad" (Mires, 2005: 195). De esta manera, lo que se configura es una sociedad en la que se abona el terreno para la producción de unos sujetos dóciles y manipulables, lo que le permite al capitalismo-neoliberal forjar relaciones sociales mercantiles. Siguiendo a Chul-Han, este tipo de relaciones se hacen visibles en la cotidianidad cuando el sujeto, que, inocentemente se asume como empresario de sí, no es capaz de establecer una relación con el otro despojada de algún interés o un fin individual cuya realización implica la cosificación del otro y, al final, de sí mismo. Esto, pues de acuerdo a este autor, "Entre empresarios (de sí) no surge una amistad sin fin alguno" (Chul-Han, 2014: p. 9).

En esta misma dirección, Foucault (2007) en su obra El Nacimiento de la Biopolítica, plantea que el empresario de sí es productor y consumidor de sí mismo, pues al consumir produce su propia satisfacción como lo hace una empresa. De esta manera, lo humano, que el liberalismo clásico jamás pudo dominar, es convertido en el neoliberalismo en objeto de comercio y mercado, como capital humano. Con esta noción el sujeto no es consciente o no le da la relevancia que se merece, a la venta de su fuerza de trabajo, ya que es el mismo sujeto quien se explota y se obliga a trabajar en condiciones indignas para satisfacer un ideal de sí, impuesto por el mercado. En otras palabras, el modelo neoliberal desideologiza a los sujetos, y en términos de Han (2014) el neoliberalismo despoja a los sujetos de su clase, elimina la clase trabajadora sometida a la explotación ajena, ya que la autoexplotación no reconoce ninguna clase porque solo trabaja por ella misma y por lo tanto "no se forma ningún nosotros político con capacidad para una acción común" (Han, 2014: 11).

En este momento, es necesario plantear que la importancia que adquiere la idea de competitividad no solo entre los empresarios y dueños de negocios de venta de bienes y servicios materiales, sino en las conciencias y prácticas de cada sujeto, en su lucha constante por alcanzar el éxito, en ambientes cada vez 
más competitivos, da cuenta de la profundidad de la hegemonía neoliberal. Es así que no solo la idea del "capital humano", deshumaniza, sino que somete a todos a la lógica darwinista, en la que solo sobreviven los "más fuertes", los "más pilos"; solo que su fortaleza y "pilera" se hace visible en las condiciones materiales que alcanza o puede alcanzar, en la capacidad de consumo que logra al hacerse más competitivo.

Retomando las reflexiones de Sánchez (1998) cuando expone que el neoliberalismo se basa también en la reestructuración de conceptos como el de soberanía, desarrollo, justicia social y democracia, se puede ver cómo, en el marco de este modelo, en esta resignificación se establece a los tres primeros conceptos, como resultado del mérito personal individual y del desconociendo al otro como sujeto social con el cual me construyo y al que ayudó a construir. Bajo este mismo marco, la idea de democracia se reduce, si a un valor universal, pero en términos de favorecer la consolidación del modelo ideológico mercantil.

Individualizada la soberanía, el desarrollo y la justicia social, despojada la democracia de todo contenido de lucha y confrontación pacífica por la construcción de un orden social deseable, la masa termina por reemplazar a la sociedad y a la comunidad. El narcisismo, de este modo, encuentra el terreno abonado para su reproducción. Esto genera dificultades para reconocer al otro y reconocerse a sí mismo como sujetos y, por tanto, imposibilita también la búsqueda constante del bienestar común (Mires, 2005). Así, lejos de promover nuevos tipos de socialización, el neoliberalismo promueve proceso de des-socialización, barbarie y re-emergencia de prácticas "primitivas". En este marco, el orden social establecido obstaculiza la sociabilidad y las redes sociales, solo sirven para la proyección de un ideal de yo, mientras en la vida cotidiana los sujetos experimentan el malestar que les produce su yo real y concreto (Mires, 2005: 203). Así mismo, por el pánico que le produce la vida real, el sujeto termina por reemplazar el contacto físico directo con el otro, por el contacto virtual, lo que le retroalimenta la des-socialización, de la que nos habla Mires. Se generan con esto subjetividades subalternas definidas por María Victoria Alvarado como "subjetividades sin un sujeto real que las habite"; subjetividades dominadas por el miedo, la ignorancia, la apatía y el aislamiento (Alvarado, et al, 2008: 10).

Bajo este marco, es de suponer que si la democracia es la forma en que la ciudadanía garantiza su participación directa, esta debería ser activa y pensada para el bienestar de todos los participantes, pero este ejercicio político ha estado también influenciado por las lógicas del capitalismo lo que hace que las actitudes (apáticas, individualistas, irreflexivas, acríticas, defensoras de "lo propio") se vean reflejadas también allí en la vida política de los sujetos. La 
noción de ciudadanía que se forma en el capitalismo contemporáneo es "una ciudadanía ligada a la propiedad y donde la organización ciudadana tiene por fin la defensa de propiedad y la preservación de las condiciones de los espacios urbanos privilegiados" (Lander, 1995: 139).

De este modo, la oligarquía neoliberal hace uso de la democracia y excluye de la discusión pública y de los procesos de toma de decisiones políticas al resto de la población haciéndole creer que participa políticamente (como otro de los engaños que se reproducen en el neoliberalismo) y es manejada como un recurso que permite a los líderes políticos obtener, con la ayuda de las técnicas mass-mediáticas, asentimiento suficiente para legitimar sus programas políticos.

\section{Socialización política y escuela}

En este apartado se hará un acercamiento a las reflexiones sociológicas clásicas y a algunos postulados del posestructuralismo, alrededor del concepto de socialización para comprender la importancia de la escuela en la formación de los sujetos sociales y en la consolidación de un proyecto de sociedad permeado por el neoliberalismo. De este modo se busca contribuir a los análisis que propenden por un cambio estructural de la escuela y de los procesos de socialización que allí se desarrollan.

Para conceptualizar la categoría de socialización, se partirá brevemente desde la perspectiva de Emile Durkheim (1986). La definición de este concepto, desde este autor, está estrechamente relacionada con su concepción de la sociedad y los modos en los que esta se reproduce. En esta concepción, las instituciones sociales, incluida la escuela, se constituyen en los escenarios en los que los sujetos son formados, moldeados de acuerdo a las formas de actuar, pensar y sentir que estas instituciones contienen y han naturalizado o normalizado. Es así que se interpreta que la socialización para Durkheim, es un fenómeno de carácter impositivo y externo, que reproduce los valores y creencias de una sociedad determinada sobre nuevos individuos, en búsqueda de constituir el ser social. La función de la escuela en esta postura sostiene que los individuos se deben adaptar o ajustar a la estructura social (este proceso es considerado positivamente pues es a partir de esto que se logra la integración social), puesto que el funcionamiento de la sociedad depende de que exista un equilibrio entre las partes que la componen, para lograr que se mantenga la estabilidad del todo.

En esta misma dirección, en las reflexiones expuestas por Emile Durkheim (1975) en su obra educación y sociología se refuta el idealismo educativo Kantiano que propone como fin último de la educación el desarrollar, de forma integral, todas las facultades humanas a la totalidad de las y los sujetos (individuos) de 

a partir de las políticas neoliberales en Colombia

la sociedad. Esto es considerado, una lectura equívoca por parte de Durkheim, ya que, para este, cada sujeto es diferente por la función social que desempeña en la sociedad, por lo tanto, la educación no puede producir niveles de vida homogéneos para todos los miembros de una sociedad determinada, aunque sí es necesario que exista una formación con aspectos comunes y generales que integren a los sujetos al contexto social al que pertenecen y así mismo sostener la cohesión y el orden social.

De acuerdo a lo anterior, el proceso de socialización que integra al sujeto en la escuela debe estar encaminado a formar un ser con las características que demanda la estructura social; es decir, la escuela, como toda institución, tiene como fin, sobre todo, la reproducción de la sociedad y garantizar su funcionamiento a través del tiempo, mediante la formación de nuevas generaciones capaces de adoptar lo que la sociedad ha acumulado en términos morales, éticos, políticos y sociales.

La educación, siguiendo a Durkheim se define como:

“...la acción ejercida por las generaciones adultas sobre aquellas que no han alcanzado todavía el grado de madurez necesario para la vida social. Tiene por objeto el suscitar y desarrollar en el niño un cierto número de estados físicos, intelectuales, y morales que exigen de él tanto la sociedad política como el medio ambiente específico al que está destinado" (Durkheim, 1975: p. 53).

Igualmente Durkheim (1975) manifiesta que la relación entre individuo y sociedad tiende a la armonía y a la normalización de las conductas, y en esto concuerda con Parsons (1986) ya que ambos, consideran que individuo y sociedad se necesitan de forma recíproca. Esto en la medida en que la sociedad recibe a nuevos sujetos que harán perdurar su funcionamiento y, por su parte, el sujeto aprende unos modos específicos de ser que le permitirán adaptarse y convivir en la sociedad donde ha nacido.

De este modo, desde una perspectiva cercana a las concepciones de Durkheim, se posiciona el estructural funcionalismo de Talcott Parsons (1986), quien define al sistema social como una relación entre dos o más actores que se ajusta a las expectativas de cada parte. Así como en Durkheim, la relación entre individuo y sociedad, no se ve como conflictiva, pues cada sistema social tiende a mantener el equilibrio, ya que es lo que resulta más provechoso tanto para el todo como para las partes. Cualquier sujeto racional buscará su mejor integración al sistema, siguiendo los lineamientos que este ha configurado para su propia reproducción. Cualquier problema entre los individuos y la sociedad, es asumido como resultado de disfuncionalidades en la comunicación entre los actores que ocupan un lugar y desempeñan un rol específico. Así, con las 
disfuncionalidades, se generan procesos de desviación de las conductas que deben ser corregidos en tanto afectan o amenazan la integración del sistema social en su conjunto.

Se deduce que esta postura simplifica la dinámica social, su complejidad, y las diferentes tensiones que ocurren en las relaciones sociales, bajo la idea de disfuncionalidades desintegradoras. Con esta mirada, como han cuestionado perspectivas marxistas o críticas, se legitiman los sistemas de valores dominantes en las sociedades modernas capitalistas y un proceso de integración social, supone la reproducción de estos sistemas de valores.

En la teoría parsoniana, la socialización se entiende como un ajustamiento al sistema social a través de la adquisición y aprendizaje de unos status-roles que llevarían al "correcto" funcionamiento de este. Dichos status-roles se encuentran determinados por el mismo sistema social, que dispone de unos mecanismos para su enseñanza, entre estos la escuela, donde la capacidad de influencia de cada sujeto en el andamiaje institucional, se reduce a los mecanismos creados por el sistema social. Cualquier innovación que cuestione la misma estructura social, es vista como una conducta desviada que el sistema, nuevamente, tiende a corregir para garantizar su propia reproducción.

Frente al estructural-funcionalismo, las perspectivas posestructuralistas, más contemporáneas y flexibles, asumen la estructura social como un campo de conflicto, en el cual interactúan diferentes tipos de intereses, que están mediados por relaciones de poder a las cuales la estructura social obedece. Para Arturo Escobar, por ejemplo; "esta tendencia del análisis social se caracteriza por haber historizado y cuestionado la universalidad de las narrativas de los saberes dominantes (...) en la reproducción (o subversión) del entramado del poder, particularmente del régimen político de la modernidad capitalista" (Escobar; 1999, p.6). De esta manera, se busca contribuir a profundizar en el análisis estructural de la realidad social y su complejidad.

Desde esta misma postura, Bourdieu (1997) califica a la posición Durkheimiana de la sociedad y la escuela, como idealismo educativo, ya que, desde Durkheim, se le impone a los sujetos un modo de vida que se considera normal o más capaz de integración social. Contrario a esto, según Bourdieu (1997), las estructuras sociales se organizan jerárquicamente de acuerdo a la distribución de los capitales y la posición social que los sujetos ocupan dentro de ella, lo que contribuye a la formación de grupos sociales que imponen relaciones de dominación sobre otros.

De acuerdo a lo anterior, los grupos sociales dominantes, tienden a determinar códigos, valores y formas de vida específicas para el desarrollo de lo que 
consideran adecuado para la sociedad, por medio del sistema educativo. Esto se argumenta con la idea de que, a partir de determinados mecanismos, como la escuela, se puede intervenir en la producción de la cultura, por ejemplo, la cultura política. De esta forma es evidente la posibilidad de que se desarrolle una vida política que tienda a la consolidación de modelos políticos definidos por los grupos sociales dominantes. Así pues, es posible identificar que estas teorías incluyen los conceptos de poder, autoridad y dominación en la noción de escuela y enfatizan en que esta reproduce tanto sus jerarquías como desigualdades (Smith, 2000).

Así, en la perspectiva bourdesiana la socialización se puede percibir como la adopción de un sistema de posiciones socialmente construidas, impuestas por mecanismos de dominación que, al reproducirse en los procesos de institucionalización, favorecen los intereses de la cultura dominante y, por tanto, de las clases dominantes. Una estructura de dominación que ha sido según Bourdieu: "(...) el producto de un trabajo continuado, histórico por tanto, de reproducción al que contribuyen unos agentes singulares (...) y unas instituciones: familia, iglesia, escuela, Estado" (Bourdieu, 2000: 50).

En este sentido, la educación para Bourdieu y Passeron (1996) no solo está presente en un sistema escolar institucionalizado, sino que se extiende de manera difusa en la formación de las sociedades y en el ámbito familiar. En todos estos escenarios, la educación y, por tanto, también la socialización, parte de una acción pedagógica que, es "una violencia simbólica" de parte de un poder arbitrario y una "arbitrariedad cultural (Bourdieu y Passeron, 1996: 45), lo que significa que sea cual sea el escenario donde se dé un modo de educación, implicará una imposición determinada por grupos o clases dominantes. La violencia simbólica que trae la acción pedagógica impacta en lo sujetos, primero porque es una exigencia determinada por relaciones de fuerza y segundo, trae consigo una "verdad objetiva" que hace que quien está siendo dominado tienda a ignorar, legitimar y reproducir la estructura de dominación de los grupos dominantes.

Es así como los actos educativos hacen parte de los sistemas sociales, reproducen estructuras de distribución de capital cultural que, del mismo modo, contribuyen a formar la estructura social. Para llevar a cabo actos educativos efectivos, la acción pedagógica establece agentes y mecanismos legítimos, como la autoridad pedagógica, que aparece como una condición que normaliza la arbitrariedad cultural que según Bourdieu y Passeron (1996) es la imposición de los sistemas simbólicos y relaciones de clase, y el desconocimiento de esta imposición, define también, los modos, medios e instrumentos de encubrimiento de esta. 
También se precisa que para que estas acciones sean homogéneas, duraderas y los sujetos logren interiorizarlas -se conviertan en habitus- el trabajo pedagógico definido por la acción pedagógica debe ser prolongado como en el caso de la enseñanza escolar. Así, en la misma dirección que el estructuralismo, la educación institucionalizada se encarga de ser un agente reproductor de los sistemas de creencias, sentidos y prácticas de las sociedades. Sin embargo, en la teoría de la reproducción cultural de Bourdieu y Passeron, se reconoce que cada acto educativo es un acto de violencia simbólica. Contrario a esto, desde las perspectivas estructural-funcionalistas, la educación sería un proceso de normalización para la conservación, en sentido positivo, de un determinado sistema social.

En suma, para la mirada posestructuralista de Bourdieu y Passeron, el sistema escolar dominante institucionalizado, a través del trabajo escolar:
“... produce y reproduce, por los medios propios de la institución, las condi- ciones necesarias para el ejercicio de su función interna de inculcación, que son al mismo tiempo las condiciones suficientes de la realización de su fun- ción externa de reproducción de la cultura legítima y de su contribución co- rrelativa a la reproducción de las relaciones de fuerza; y (...) por el solo hecho de que existe y subsiste como institución, implica las condiciones institucionales del desconocimiento de la violencia simbólica que ejerce, o sea, porque los medios institucionales de los que dispone como institución relati- vamente autónoma, detentadora del monopolio del ejercicio legítimo de la vio- lencia simbólica, están predispuestos a servir además, bajo la apariencia de neutralidad, a los grupos o clases de las que reproduce la arbitrariedad cultu- ral..." (Bourdieu y Passeron, 1996: 108).

Bajo una mirada posestructuralista, diferente a la perspectiva bourdesiana, ubicamos a los sociólogos Peter Berger y Thomas Luckmann (2003), quienes teorizan que el proceso de socialización comienza en la primera infancia. En esta etapa el sujeto es incapaz de identificar en sí mismo un yo y por lo tanto, es incapaz de reconocerse como actor social. De ahí que necesite del acompañamiento de su madre y de su núcleo familiar en general. Esta etapa es identificada por los sociólogos como socialización primaria. Por su lado, la socialización secundaria se entiende como el proceso a partir del cual el sujeto reconoce que el mundo de los padres no es el único, y por lo tanto, su desarrollo se establece a partir del orden cultural y social, adquiriendo conocimiento específico de roles dentro de un contexto institucional establecido por la sociedad, y reforzado por técnicas pedagógicas específicas.

En tal sentido, los sujetos construyen la sociedad y la sociedad construye los sujetos, es decir se produce a partir de una realidad objetiva y realidad 
subjetiva. En la misma dirección que Parsons, establecen que existen ciertas instituciones (o un proceso de institucionalización) que determinan tipos de actores, establecen pautas y mecanismos de sanción. Así como en la aprehensión de roles que están impuestos por instituciones y que, por medio de mecanismos generacionales y reglas de comportamiento, legitiman un orden institucional.

Todas estas perspectivas manifiestan que la socialización escolar se ha constituido como un mecanismo de producción y reproducción de determinadas formaciones sociales establecidas por grupos dominantes, lo que nos conduce a cuestionarnos sobre los cambios económicos y culturales del contexto contemporáneo y su injerencia en los procesos de socialización, y del mismo modo los tipos de sujetos que crea.

\section{Repensar el sujeto: subjetividades políticas en la escuela}

Este apartado está orientado a determinar las manifestaciones concretas a través de las cuales se pueden identificar los impactos del neoliberalismo en la construcción de las subjetividades en las sociedades contemporáneas. Esto, teniendo en cuenta que las subjetividades se construyen a partir de los procesos de socialización y estos, están a la vez afectados por las transformaciones institucionales y políticas derivadas de las orientaciones sociales dominantes.

Así, en primer lugar, se puede ver que, según Palacios y Herrera (2013) la subjetividad es una categoría emergente que en los debates contemporáneos ha ganado una gran relevancia ya que es útil para abordar la relación entre sujeto y sociedad o más bien entre el sujeto, la sociedad y las instituciones políticas. De acuerdo a los estudios de Sabucedo (1996) la subjetividad se entiende como un proceso complejo y general de la configuración política de cada ser humano individualmente considerado. El estudio de las subjetividades se desarrolla a partir del análisis de los procesos de socialización. Estas no se entienden como entidades unívocas, homogéneas, cerradas, sino más bien, en las sociedades contemporáneas, como múltiples y contradictorias, en construcción permanente, tanto de un "sí mismo", como en la relación con los demás (Mouffe, 1994).

Para comprender un poco más los procesos de construcción de la subjetividad, es necesario aclarar que esta supone, necesariamente, que cada sujeto establezca vínculos con los demás a partir del reconocimiento de aquellos, como subjetividades siempre en construcción. En las sociedades actuales, precisamente la fuerza del neoliberalismo conduciría a la construcción de subjetividades cerradas sobre sí mismas; que se leen y reconocen como construcciones inacabadas, pero no logran ver esto en los demás. Es precisamente estas subjetividades 
cerradas sobre sí mismas las que se entienden a partir del individualismo (Mirés, 1998) o a partir de la categoría "subjetividades subalternas" (Alvarado, 2008). Esta última categoría, es necesario aclarar, da cuenta de cómo estas subjetividades, egoístas o individualistas, terminan por ser, así mismo, pasivas. La configuración de esta pasividad de los sujetos, podría haber estado influenciada por la transformación de los sistemas escolares y los énfasis en estos en la competencia con el cercano y el establecimiento de relaciones interpersonales instrumentales.

La configuración del sujeto neoliberal, de este modo, atravesaría la configuración de las instituciones escolares, cuyas finalidades se centran en el incremento de su capacidad productiva de sujetos productivos y competitivos. La socialización escolar estaría presionando a la configuración de estas relaciones mediadas por la competencia y el interés, pero también estaría contribuyendo a la naturalización de las desigualdades sociales. El individuo termina por aceptar, como naturales o normales, las condiciones de desigualdad y empiezan a ver que la única manera de romper con esta, es mediante el esfuerzo personal-individual, con la lucha aislada y sacrificada por "salir adelante" y "ser alguien en la vida", discurso instalado en la "subjetividad de las estructuras mentales" (como diría Bourdieu) de muchos de nuestros jóvenes. Una escuela neoliberal, así, produce, por otro lado, la aceptación del destino de los más pobres, que se forman para el trabajo y la aceptación naturalizada de su condición de subalternidad. Las clases medias y altas, por el contrario, edifican sus proyectos de existencia gozando de las ventajas comparativas y competitivas de sus propias condiciones de clase, unas para la administración de la estructura de poder, las otras para la dirección de estas mismas estructuras.

El estructural-funcionalismo, sería la perspectiva teórica más acorde con esta naturalización de las relaciones de poder y dominación que la escuela está contribuyendo a producir y reproducir. Los teóricos de la educación que impulsan programas como "ser pilo paga", y que legitiman la financiación de la demanda, más que de la oferta, contribuyen a la reproducción de la hegemonía neoliberal en la que se vende la idea de que todos estarían dotados de las mismas competencias y habilidades para "salir adelante" y romper los obstáculos que, desde esta perspectiva, más que estar en la "objetividad de las estructuras sociales" como diría Bourdieu, estarían exclusivamente en la "subjetividad de las estructuras mentales" (Bourdieu, 2011).

Bajo este panorama, es evidente que si hoy en día es necesaria la reflexión de la realidad social en su complejidad, también es necesaria la construcción de otras visiones de sujeto más amplias que, tal como lo plantea Sara Victoria Alvarado "necesitan ser renombradas, resignificadas atendiendo más a sus propias realidades que a las abstracciones formales enunciadas desde los ideales de perfección de la 
modernidad" (Alvarado, et. al, 2008: 08). Así pues, la construcción de subjetividades requiere sujetos que conocen, cuestionan y critican su realidad social, no se trata de individuos inermes ante lo que ocurre en su propio entorno (Palacios y Herrera, 2013).

El fortalecimiento de la subjetividad política propone rescatar la noción de sujeto y transformarla. Esto implica potenciar y desarrollar sus tramas y cualidades como la autonomía, la reflexividad y la conciencia crítica; característica que son propias de la conformación de subjetividad política como categoría que se propone desarrollar al sujeto en su enteridad. De acuerdo Mafessoli citado por Alvarado (2008) "la expresión de la totalidad del sujeto en su complejidad, no el sujeto-razón sino el sujeto en sus múltiples dimensiones (cuerpo, emoción, sentimiento, razón, etc.) y en sus múltiples condiciones identitarias". No obstante la sociedad nos construye, casi en un $100 \%$, pero aquí, la no totalidad de esta construcción como sujetos, nos posibilita unos espacios de apertura, de transgresión, de problematización y cuestionamiento de lo instituido. No hay socialización completa, de haberla no solo estaríamos sujetados, sino que seríamos autómatas, respondiendo mecánicamente a los mandatos sociales. He ahí el espacio de la política (Castoriadis, 2002), y también, para nuestro caso, el desarrollo de las subjetividades políticas. Es así como el desarrollo de dichos espacios, en la construcción de cada sujeto, posibilitan la acción política y la conformación del pensamiento crítico.

Teniendo en cuenta el proceso de modernización y la vinculación del sistema educativo con la economía de nuestras realidades concretas, la categoría de subjetividad política es de este modo, una categoría fundamental para reflexionar sobre la educación y la situación de esta en la actualidad. Esta categoría se constituye como un núcleo que permite abordar las problemáticas emergentes, así como analizar el conjunto de percepciones, sentires, creencias e intereses que orientan las prácticas sociales de los sujetos en sus manifestaciones concretas (Palacios y Herrera, 2013). Sin embargo, para contribuir a la formación de sujetos críticos, emancipados, reflexivos y propositivos, que posiblemente configuren múltiples realidades para articular tanto lo individual como lo colectivo, el desarrollo de la subjetividad política debe ir ligado al de la conciencia histórica y hacia el valor de lo público. Tal como propone Alvarado (2008) el desarrollo de la conciencia histórica se da por medio de la ubicación en tiempo y espacio específicos. Con la comprensión de la historia propia se generan la reflexividad, el reconocimiento de la realidad y la conciencia para intervenir en ella desde la praxis (reflexión palabra-acción) Arendt (1997).

En esta dirección, se asume que la construcción de subjetividades políticas es contextual y que se da en la relación constante con el otro y se concluye que el desarrollo de estas es producto de escenarios de socialización política que se 
ocupan de integrar a los sujetos y adaptarlos a nuevos contextos sociales. El concepto de socialización política puede entenderse desde distintas perspectivas. Funes (2003) lo define como "un proceso mediante el cual la gente adquiere orientaciones consistentes en cuanto a la política en general y en relación con los sistemas políticos en particular" (p. 190). Esta perspectiva deviene de una concepción clásica del estructural-funcionalismo norteamericano (Ver Easton, 1959), que reduce lo político al sistema político y a las instituciones políticas. De este modo, la socialización política se entiende como el proceso a través del cual los sujetos incorporan percepciones sobre estas instituciones y desarrolla (o no) una cultura cívica (De la Roche, 2000). Desde una perspectiva similar a la anterior, el concepto de socialización política se entiende como "un elemento que se ajusta y prepara a los individuos para el ejercicio de roles asignados o adquiridos socialmente" (Smith, 2000: 1).

Con algunos matices diferentes, la perspectiva de Lozano (2008) plantea el concepto de socialización política como "el proceso mediante el cual un individuo aprende a ser miembro de una sociedad y a ser él mismo" (p. 350). Este último elemento, se considera, abre la posibilidad de pensar al sujeto, como aquel que se configura si, en relación con la sociedad, pero no solo aprehende, incorpora roles y posiciones o percepciones sobre el sistema político, sino además, construye sus propias visiones del mundo, se interroga. Este sujeto que "aprende a ser él mismo", en la expresión de Lozano, se construye a la vez que es construido.

Buscando una síntesis entre las tres definiciones expuestas es posible visibilizar elementos comunes que definen a la socialización política como todo aprendizaje político que le permite al sujeto aprender y desempeñar roles sociales tanto en el ejercicio de lo público, como en la esfera personal.

Así pues, los procesos de socialización política entendidos como procesos de aprendizaje se manifiestan en espacios donde los sujetos interactúan entre sí ya que mediante esta multiplicidad de interrelaciones el sujeto moldea su conducta de tal forma que genere un habitus acorde con la información recibida e interiorizada en cada espacio. Se puede deducir también que los procesos de socialización política contribuyen a la formación de subjetividades políticas lo que debería conducir al desarrollo de una conciencia histórica y un pensamiento reflexivo y crítico en los sujetos, especialmente en la escuela como agencia de formación y espacio de socialización.

Los estudios desarrollados para definir a la socialización política como categoría, se enmarcan en primer lugar en identificar aspectos de la formación, que, desde la institucionalidad, contribuirían a mantener el orden democrático y la conformación de ciudadanos que correspondan a dicho orden en el 
plano de las instituciones de gobierno (Palacios y Herrera, 2013). Pero si bien la socialización política en su primer momento estudió los factores que influyen a formar determinado tipo de conducta; estudios recientes complejizan esta noción como confirma Alvarado (2008) donde en la actualidad debe estar vinculada con los procesos de formación ciudadana teniendo en cuenta el contexto social del sujeto y la multiplicidad de dimensiones que lo configuran: afectivas, emotivas, cognitivas, psíquicas, intersubjetivas, etc.

La escuela como espacio de socialización tiene la tarea de contribuir a complejizar estos procesos de socialización política pues como se ha señalado, es mediante estos que los sujetos aprenden a interiorizar los valores sociales y sus nociones políticas adquiriendo una posición en la sociedad y por lo tanto, manifestando un comportamiento social acorde con la estructura social actual. Se podría decir, siguiendo a Mires (2005), que las relaciones interpersonales concretas, cotidianas e incluso íntimas, son los espacios en los cuales se forma también lo político, se prepara al sujeto para la interacción ciudadana, con desconocidos. No se trata, por tanto, de apostarle a una formación política que presente el "valor" o el "sentido" de las instituciones políticas y contribuya a la construcción de lo que las perspectivas estructural-funcionalistas, denominaron cultura cívica, sino a la politización, problematización de la vida cotidiana, que es donde se configuran lo sentidos sobre el poder y las relaciones de poder (Castoriadis, 2011, Mouffe, 1994).

De esta forma, reconociendo la importancia histórica que ha jugado la escuela y la educación en el fortalecimiento y mantenimiento del orden social, como institución propia de la estructura hegemónica, se plantea como tarea urgente y absolutamente necesaria una reconfiguración de las mismas desde una postura alternativa y crítica que reconozca como principios básicos la igualdad, la diversidad y el reconocimiento de los otros, pero sobre todo reconocer la educación como un ejercicio y proceso constante de reconfiguración de los sujetos, sus construcciones no solo de sí, sino de su vida en sociedad.

\section{La pedagogía crítica como alternativa}

El campo de la pedagogía y de la pedagogía crítica en particular, asume el problema de los deseos, las identidades, las subjetividades de distinto tipo, no solo como objeto de reflexión académica sino como campo de intervención política. Se hablaría entonces de pedagogías del deseo o de los deseos, pedagogías de los valores y de las subjetividades y en esta dirección de las identidades, entre otras. De este modo a lo que se le apuntaría es a la politización, en el sentido más radical, de estos procesos, desde el punto de vista educativo. Politización entendida como la formación política, que entienda a la política como el cuestionamiento explícito y lúcido de las instituciones establecidas y la 
búsqueda, también explícita y lúcida de las instituciones deseables (Castoriadis, 2001). Es creación, acción creadora pero, sobre todo, discurso, opinión sobre el orden establecido y sobre el orden social deseable (Mouffe, 1994, Arendt, 1997). De ahí que, para su ejercicio, sean necesarias unas condiciones.

Reconociendo que en la actualidad vivimos una crisis de la política (Mires, 2005), en la que se hace cada vez más difícil asumir a esta como espacio de construcción de lo colectivo en colectivo y escenario de trámite de los conflictos que caracterizan a toda sociedad. Aceptando, por tanto, que vivimos en una crisis de la democracia como régimen de auto institución explícita y lúcida de las instituciones deseables; como un régimen en el que lo público se hace en público; en fin, como un régimen de auto limitación y autorregulación en el que la autonomía social e individual es un proyecto fundamental (Castoriadis, 2004); la tarea de la escuela se convierte en prioritaria para la reconstrucción de la política y de la democracia contra el neoliberalismo despolitizador. Dentro de este marco, la política se ha convertido en politiquería, pues su significado está reducido a las inferencias que se derivan de la información mediática sobre la actividad de los políticos profesionales y se niega como proceso y espacio para crear opciones de ordenamiento social democrático. De ahí la importancia de la politización de la vida cotidiana; es decir, de la apertura de esta vida cotidiana a todo tipo de cuestionamiento.

El concepto pedagogía crítica emerge en los Estados Unidos en los años ochenta, a partir de un grupo de pensadores norteamericanos (Giroux, McLaren, entre otros) desarrollado en Latinoamérica desde referentes como Paulo Freire, el Ejército Zapatista de Liberación Nacional en México y el movimiento sin tierra en Brasil. El hecho de haber nacido allí generó dificultades para que se extendieran los planteamientos de la pedagogía crítica en América Latina y fue solo con la traducción de los primeros libros de Giroux y McLaren, que comenzó a reconocerse que los planteamientos podrían contribuir al desarrollo de nuevas prácticas interpretativas y de conocimiento que podrían ayudar a romper con obstáculos generados por la dependencia, la dominación y la explotación en América Latina desde el campo de la educación.

En primer lugar, las pedagogías críticas son el resultado de procesos multivariables en los que los pueblos afrontan sus propios procesos educativos con una perspectiva transformadora. Los ejes, problemas y énfasis de las pedagogías críticas están mediados por los procesos históricos particulares de cada sociedad y por los problemas que cada sociedad siente como prioritarios o determinantes. Lo popular, la explotación, la discriminación social, la exclusión, el autoritarismo, son propios de las sociedades latinoamericanas, y es a partir de estos que educadores de nuestro continente se han asumido como protagonistas. 
De este modo, las pedagogías críticas como concepto englobante de diversos procesos, establecen interconexiones y aprendizajes mutuos en las prácticas pedagógicas críticas que entren a profundizar y radicalizar los procesos de transformación necesarios en los distintos campos de la vida social.

Puntualmente, se empieza a asumir la pedagogía crítica como aquella que:

\begin{abstract}
"interroga analíticamente, y consecuentemente desafía, las condiciones actuales de injusticia e inequidades sociales existentes y que día a día se están extendiendo en nuestras sociedades (...) Por tanto, la pedagogía crítica busca al mismo tiempo la transformación de las personas como de las mismas condiciones concretas que pone bajo análisis, porque cuando las personas desarrollan análisis complejos de las relaciones entre lo global (condiciones políticas, económicas, culturales entretejidas con los sistemas de opresión) y lo concreto (situaciones de la vida diaria, politicas y procedimientos específicos que se expresan a nivel de las instituciones, de las familias, de los espacios sociales) promueve procesos de empoderamiento de las personas que los llevan a tomar consciencia de su situación histórica como sujetos que dialécticamente son parte y constructores de la historia... de su historia. La pedagogía crítica pone bajo análisis las concepciones acerca de educación, escolaridad, cultura y sociedad que tomamos como-dadas o de sentido común. Al mismo tiempo, proporciona un marco teórico para analizar las interacciones de poder/conocimiento mientras reconoce las voces de las estudiantes y maestras en el proceso de llegar a ser conscientes de su propia situación histórica, económica y política y así poder actuar sobre ellas para transformarlas" (Anglás-Grande, 2000; Giroux, 1983; 1988b; McLaren, 2003; Morales, 1996). (Huertas-Charles; 2003: 115).
\end{abstract}

Así, la escuela podría orientar su desarrollo hacia escenarios de construcción social de conocimiento en correspondencia con las necesidades e intereses del sujeto mismo y de su comunidad. Para McLaren (2015) el currículo en la escuela debe encaminarse a ayudar a asumir desde el proceso de escolarización las dimensiones sociales, políticas, culturales y económicas, por otra parte, asumir también la vida escolar como un terreno cultural, un escenario para la pluralidad, las luchas y el conflicto, pero también para diferentes grados de acomodación, contestación y resistencia. Así mismo, entendiendo esto, los actores educativos podrían llegar a empoderarse para la formación de conocimiento y nuevas relaciones sociales, donde aprendan a cuestionar y a apropiarse de aspectos culturales dominantes para así poder transformarlos.

Se trata, desde la reconstrucción de la pedagogía crítica, de mantener la capacidad de transformar la realidad social desde la educación y a través de los recursos pedagógicos disponibles o por construir. En palabras de Marco Raúl 
Mejía (2001: 100) “Este posicionamiento exige una disposición a que los procesos educativos y pedagógicos, desde su especificidad, construyan un mundo sin exclusión y visibilicen las voces y las condiciones de ellos y su lugar en la sociedad, así como sus culturas y derechos". En este sentido el autor señala que la pedagogía crítica en la escuela debe posibilitar la reflexión autónoma de la realidad por parte del sujeto en su contexto y desde su lugar, pero también movilizar a la acción y al cuestionamiento permanente dentro de ella, reconociendo estos elementos como propios de la transformación pedagógica. Transformación de condiciones de dominación, reconociendo también que la pedagogía crítica como reflexión educativa entra en disputa con los diferentes intereses que pretenden la hegemonía y determinar el devenir de estas sociedades.

Desde el punto de vista del trabajo del aula, el profesor que pretenda impulsar el desarrollo del pensamiento crítico, debe asumir una actitud que posibilite que los estudiantes desarrollen sus propios procesos de interpretación, análisis y síntesis, frente a los problemas que se le planteen y que estos vayan planteando por sí mismos en las interacciones escolares, hasta generar procesos autónomos de problematización tanto del conocimiento específico de cada área, como frente a la vida cotidiana.

Siguiendo este camino nos proponemos definir el desarrollo del concepto de pensamiento crítico, y su importancia en la construcción de una acción política encaminada hacia la transformación de las prácticas escolares. Así, tal como lo expresa Agustín Campos Arenas (2007) citando a Huitt (1993), el pensamiento crítico se definiría como:

"En primer lugar, se considera una "habilidad de analizar los hechos, generar y organizar ideas, defender opiniones, realizar comparaciones, derivar inferencias, evaluar argumentos y resolver problemas. En segundo lugar, se reconoce como una forma de razonamien to que demanda adecuado apoyo para las propias creencias y una indisposición a ser persuadido a menos que se presenten evidencias. En tercer lugar, se considera como un proceso consciente y deliberado que se usa para interpretar o evaluar información y apariencias con un conjunto de actitudes y habilidades reflexivas que guian creencias y acciones pensadas. En cuarto lugar, se asume como un proceso activo y sistemático de comprensión y evaluación de argumentos. Un argumento provee la certeza de la afirmación acerca de las propiedades de un objeto o las relaciones entre dos o más objetos y evidencia el apoyo o rechazo de la afirmación" (Campos, 2007: 37).

A partir de estas características es posible evidenciar que el pensamiento crítico es un proceso de construcción de habilidades de análisis, interpretación y reflexión sobre el mundo que se enfrenta con "actitud" interrogativa. Aquí 
cabe aclarar que no se establece una forma única de comprender y analizar argumentos, sino que cada sujeto, de acuerdo a su propio proceso, toma postura desde creencias y sentires que intenta defender con argumentos reflejados frente a un problema, que implique toma de decisiones o resolución de problemas. Del mismo modo, se asume que los sujetos deben ser capaces de escuchar a los otros, que analizan e interpretan las afirmaciones de los demás como las propias, para llegar a conclusiones consensuadas, desde una actitud reflexiva, crítica y consciente. Se apunta en esta dirección a la construcción de sujetos que reconocen la diversidad de puntos de vista, que asumen sus propias posiciones como una más entre otras, sin que esto signifique que toda postura vale, sino que es, parafraseando a Chantal Mouffe (1994), validable en tanto sea argumentada, reconociendo como elemento constitutivo de todo sujeto, que no solo está hecho de reflexiones y razones, sino de emociones y afectos que constituyen identidades móviles y que no necesariamente, estos y aquellas logran reducirse "racionalmente", sino que, de hecho deben hacerse visibles.

Los jóvenes no se identifican únicamente como hijos, amigos, estudiantes, etc., sino que se relacionan con grupos de consumos culturales como los ritmos musicales; o las corrientes ideológicas, o las etnias. Y al hacerlo se encuentran insertos en procesos globales de construcción de la identidad y desde este lugar se proyectan políticamente. De ahí que siguiendo a Chantal Mouffé y Ernesto Laclau, cada vez que hablamos de sujeto, es mejor hablar de distintas posiciones de sujeto (Mouffe, 1994; Mouffe y Laclau; 2006).

Según Leivas (2013) quien retoma a Gramsci en la reflexión pedagógica, toda intención que la escuela posea de formar a los sujetos para elevar los niveles de consciencia de sí mismos, sus niveles de autonomía y de crítica, se ha pasado a considerar como un despilfarro del gasto público. Resalta que Gramsci aborda las relaciones de hegemonía como relaciones pedagógicas. Teniendo en cuenta que si la lucha es contra-hegemónica también debe ser contra-pedagógica pues es en la escuela donde se reproduce esta concepción de mundo. El docente como mediador de la cultura a través de su práctica debe transformar las concepciones hegemónicas de la realidad. El principio educativo de Gramsci es abordar estas relaciones pedagógicas como relaciones de poder que legitiman unos valores elitistas y contradictorios con la vida material específica o en sus términos conciencia práctica de los sujetos.

La función "contra-pedagógica" del docente, desde Gramsci, es generar experiencias sintéticas, artísticas y psicológicas para que luego sean reflexionadas en la conciencia teórica del sujeto, entendiendo esta como su forma de percibir el mundo y leer su realidad social para que sea coherente con su conciencia práctica, es decir, su vida cotidiana y responda a tales necesidades desde 
una praxis crítica. Por lo tanto la tarea del docente es guiar a los sujetos a reconocerse a sí mismos como sujetos históricos y críticos de la realidad.

Es entonces necesario plantear como la tarea de los educadores y desde la praxis crítica como reflexión de la teoría con la práctica, quienes, asumiendo la propuesta esbozada desde la pedagogía crítica y la formación de subjetividades políticas, podrían examinar y desmontar las tradiciones educativas, y de la misma manera, contribuir a formar una sociedad que sea económica y socialmente más justa. La invitación es a repensar la práctica pedagógica en función de las pedagogías críticas, a cuestionar y deconstruir los discursos que reproducen estructuras hegemónicas. A transformar y construir escuela desde la resistencia, la denuncia, las políticas del reconocimiento, las actuaciones éticas y una revolución de la política.

\section{CONCLUSIONES}

De acuerdo a lo interpretado, se hace evidente que la tendencia a la neoliberalización de la educación en Colombia ha ido incrementando a través del tiempo -aún con la oposición de ciertos sectores sociales- factor que ha favorecido las conflictividades y tensiones entre los actores educativos y, por otro lado, la formación de sujetos neoliberales para una sociedad neoliberal. Los discursos neoliberales, han logrado imponerse de manera sistemática en el sistema educativo colombiano, mediante la implementación de políticas que buscan la conversión de la escuela en una máquina productora de sujetos sumisos y flexibles ante la inflexibilidad del capital. Estos discursos han guiado las principales reformas del sistema educativo colombiano de las últimas décadas, en el campo administrativo, evaluativo, pedagógico y curricular. La imposición de ciertas temáticas, como el emprendedurismo y las lógicas de la "eficiencia administrativa", con todo su andamiaje institucional, ha buscado debilitar cualquier forma de resistencia.

No obstante este predominio neoliberal en la orientación del sistema educativo colombiano, resalta la importancia de recuperar el sentido político de la educación y el lugar de la escuela como escenario de disputa política. En este sentido, se hace necesario reconocer el valor histórico que ha jugado la escuela y la educación en el fortalecimiento y mantenimiento de un orden social que ha tendido históricamente a reproducir la estructura social dominante. Derivado de esta postura, se plantea como tarea urgente y absolutamente necesaria una reconfiguración de la escuela desde una postura alternativa y crítica que reconozca como principios básicos la igualdad, la diversidad y el pensamiento crítico, reconociendo a la educación como un ejercicio y proceso constante de reconfiguración de los sujetos, como un escenario para la construcción 
del bienestar colectivo y para la construcción social de conocimiento en correspondencia con las necesidades e intereses del sujeto mismo y de su comunidad, más allá de lo que los defensores del mito del libre mercado, han establecido como un imperativo naturalizado.

A partir de esta postura, se ha pretendido contribuir a la construcción de propuestas colectivas desde diferentes focos de resistencia, tomando conciencia de las condiciones objetivas de la realidad, y aterrizándolas a las subjetividades, asumiendo posiciones políticas e históricas que posibiliten escenarios de participación y alternativas a las dinámicas impuestas por los capitales dominantes. Se reivindica con esto, el papel de los docentes y los demás actores escolares como partícipes de la posibilidad de reconfiguración de la escuela, comprendiendo la profundidad de la hegemonía neoliberal y buscando alternativas de transformación. Para tal fin, se resalta el papel de la pedagogía crítica, como un enfoque que busca romper las fronteras impuestas; contribuir al desarrollo del pensamiento crítico (entendido más allá de lo instrumental) y encaminar a los sujetos al fortalecimiento de su autonomía y empoderamiento.

\section{REFERENCIAS}

Alvarado, S. Ospina, H., Botero, P. y Muñoz G (2008). Las tramas de la subjetividad política y los desafíos a la formación ciudadana en jóvenes. Revista argentina de sociología año $6 \mathrm{~N}^{\circ} 11$.

Alvarado, S. V., Ospina-Alvarado, M. C. \& García, C. M. (2012). La subjetividad política y la socialización política, desde las márgenes de la psicología política. Revista Latinoamericana de Ciencias Sociales, Niñez y Juventud, 10 (1):235-256.

Anderson, P (2003). La Trama del Neoliberalismo. Mercado, crisis y exclusión social. Buenos Aires. CLACSO.

Arias, D (2009). Políticas públicas y crisis de la pedagogía en Colombia. Rollos nacionales. Enero-junio; 3(26): 68-80.

Arendt, H. (1997) ¿Quées la política? Traducción de Rosa Sala Carbó. Editorial Paidos, Barcelona.

Asnar, P y Gómez, V (Febrero 1 de 2016). "Los alcances del 'Ser Pilo Paga' son excesivamente limitados". El Espectador. Recuperado de: http:/ / www. elespectador. com/ noticias/educacion/los-alcances-del-ser-pilo-paga-son-excesivamente-limita-articulo-600089 
Berger, P y Luckmann, T (2003). La construcción social de la realidad. Buenos Aires: Cultura Libre.

Bocanegra A., H (2006). Globalización y política educativa en Colombia. Revista Diálogos de Saberes (enero - junio), 24;33-50.

Blanco S. Jorge O. (2004). “Globalización, Movimientos Sociales y Ciudadanía”. En: Diálogo de Saberes. Revista del Centro de Investigaciones Socio-Jurídicas, de la Universidad Libre. No. 20. Bogotá; Enero-Junio de 2004. pp. 149-172. ISSN. 0124-0021 Revista Indexada por Colciencias.

Blanco , J (2014). Educación superior, crédito educativo y equidad en Colombia 1992 2011. En: Diálogos de saberes, Bogotá D.C. Colombia • 40:139-155.

Bourdieu P (2000). La Dominación Masculina. Barcelona: Anagrama.

(1997). Razones prácticas sobre la teoría de la acción. Barcelona: Anagrama.

(2011). Las estrategias de reproducción social. Traducción de Alicia Beatriz Gutiérrez, Siglo XXI Editores: Buenos Aires.

México: Fontamara.

, Passeron, J (1996). La Reproducción. Elementos para una teoría de la enseñanza.

Castoriadis, C (2004). Figuras de lo pensable. Las encrucijadas del laberinto VI. Fondo de Cultura económica, México.

(2002). Poder Política, autonomía. Edición digital en. www.edu. mec.gub.uy poder política y autonomia.pdf.

(2011). "La democracia como procedimiento y como régimen". Traducción de Aurelia Álvarez, Edición digital en: Leviatan, No. 62:65-83. Link. http: / / prensahistorica.mcu.es/es/consulta/registro.cmd?id=1010269

Chul-Han, B (2014). Psicopolítica. Barcelona: Herder.

Convenio Interadministrativo entre el Servicio Nacional de Aprendizaje "SENA" y la Secretaría de Educación Distrital de Bogotá para el desarrollo del Programa de Articulación. Febrero de 2005.

De la Roche, F., 2000. “Aproximaciones al concepto de cultura política”, En: Convergencia, Revista de Ciencias Sociales, 7(22):93-123.

Deleuze, G y Guattari, F (1973). El antiedipo: capitalismo y esquizofrenia. Barcelona: Barral, pp. 33-42. 
Díaz, C y Celis, J (2010). Efectos no deseados de la formación para el trabajo en la educación media colombiana. Educación y Educadores 13(2):199-216.

Dinero, 4-27-2001. Los 100 colegios del 2000. Recuperado de: http:/ / www. dinero.com/ pais/articulo/los-100-colegios-del-2000/8834

Durkheim, E (1973). Educación y sociología. París: Península. México D.F.

(1986). Las reglas del método sociológico. Fondo de cultura económica S. A.:

El espectador, 6-12-2015, "Roberto Zarama, el arquitecto de Ser Pilo Paga". http:/ / www.elespectador.com/noticias/educacion/roberto-zarama-el-arquitecto-de-serpilo-paga-articulo-603681

Escobar, A (1999). El final del salvaje. Naturaleza, cultura y política en la antropología contemporánea. Bogotá: ICAN-CEREC.

Estrada, J (2003-2004). Transnacionalización y mercantilización de la Educación pública. Taller: revista de análisis de la actualidad política (Bogotá) 7:59-75.

(2010). Privatización y mercantilización de la educación pública estatal, otra muerte anunciada: A propósito del Decreto 2355 del 2009. Educación y Cultura. $87: 18-24$.

(2004). Construcción del modelo neoliberal en Colombia 1970-2004. Colombia: Aurora.

Foucault, M (2007). Nacimiento de la Biopolítica. Curso en el Collège de France. Fondo de Cultura Económica.de Argentina.

Fromm, E (1941). Miedo a la libertad. Farrar \& Rinehart.

Funes, M (2016). Socialización política y participación ciudadana. Jóvenes en dictadura y jóvenes en democracia. Edición digital.

García, M y Quiroz, L (2011). Apartheid educativo: educación, desigualdad e inmovilidad social en Bogotá. Revista de Economía Institucional. 13(25):137-162.

Huertas-Charles, L (2007). Una breve historia de la pedagogía crítica: la experiencia norteamericana. En: García Quintanilla, Magda (Comp.). Voces y paradigmas de la educación. Universidad Autónoma de Nuevo León, Monterrey, pp. 105-142.

Internacional de la Educación para América Latina. IEAL (2015). La estandarización de la evaluación. Las pruebas nacionales e internacionales ¿medición o evaluación? 
Lander, E (1995). Neoliberalismo, sociedad civil y democracia. Ensayos sobre América Latina y Venezuela. Universidad Central de Venezuela.

Laval, C. (2004). La escuela no es una empresa. El ataque neoliberal a la enseñanza pública. Barcelona: Paidós.

Leivas, M (2013). Introducción al pensamiento pedagógico de Antonio Gramsci Estado educador, escuela, y lucha contrapedagógica. Tandil. ISSN 1852-2459 6(10):104-117.

Ley 1014/2006 de Fomento a la Cultural del Emprendimiento. Congreso de la República de Colombia. Enero 26 de 2006.

Lizarazo, F. (2008). Efectos del decreto 230 del 11 de febrero de 2002 en la comunidad educativa del Instituto Técnico Industrial Piloto Sede A jornadas mañana y tarde (Tesis de Maestría). Universidad Externado de Colombia, Bogotá.

Lozano, M (2008). Los procesos de subjetividad y participación política de estudiantes de psicología de Bogotá. Revista Diversitas, perspectivas en psicología 4(2):345- 357.

McLaren, P (1997). Pedagogía crítica y cultura depredadora. Políticas de oposición en la era posmoderna. Barcelona. Paidós Educador. RIEJS 4(2):29- 66.

Mézáros, I (2008). La educación más allá del capital. CLACSO.

Miñana, C (2010). Políticas neoliberales y neoinstitucionales en un marco constitucional adverso. Reformas educativas en Colombia 1991-2010. Propuesta Educativa, 34:37-52.

y Rodríguez, J (2002). La educación en el contexto neoliberal.

Mires, F (2005). El malestar en la Barbarie. Erotismo y cultura en la formación de la sociedad política. Texas: Nueva Sociedad

Mouffe, Ch (1994). La democracia Radical ¿Moderna o postmoderna? En: Revista Foro. No. 24. Las incertidumbres de la democracia. pp. 13-23.

y Laclau, E (2006). Hegemonía y estrategia socialista. Hacia una radicalización de la democracia. FCE, México.

OCDE y MEN (2016). Revisión de politicas nacionales de educación: La educación en Colombia. Organización para la Cooperación y el Desarrollo Económicos (OCDE), París.

Palacios, N, Herrera, J (2013). Subjetividad, socialización política y derechos en la escuela. Revista Internacional de Investigación en Educación. 5(11):413- 437 
Parsons, T (1986). El sistema social. Madrid: Ediciones de la revista de Occidente. Capítulo 6. El aprendizaje de las expectativas sociales de los roles y los mecanismos de socialización de la motivación, pp. 132-161 (en versión digital)

Puigross, A (1996). “Educación neoliberal y quiebre educativo". En: Nueva Sociedad Nro. 146 Noviembre-Diciembre 1996, pp. 90-101

Sabucedo, J (1996). Psicología política. Editorial Síntesis, Madrid

Sánchez, G (1998). El asalto neoliberal. En libro: Los retos de la globalización. Ensayo en homenaje a Theotonio Dos Santos. Francisco López Segrera (ed.). UNESCO, Caracas, Venezuela. 1998. ISBN: 9291430366 . Disponible en la World Wide Web: http:// bibliotecavirtual

Sánchez, T (2015). Aproximación a un estudio genealógico de la evaluación educativa en Colombia, segunda mitad del siglo XX. Bogotá: UD.

(2013). La evaluación educativa como dispositivo de constitución de sujetos. Revista Latinoamericana de Ciencias Sociales, Niñez y Juventud, 11(2): 755-767.

Semana, 28-06-2016. “Universidades privadas reciben el 98 \% de los recursos de Ser Pilo Paga", http:// www.semana.com/educacion/articulo/ser-pilo-paga-universidades-privadas-reciben-dinero-de-ser-pilo-paga/479620.

Smith, M (2000). Educación, socialización política y cultura política. Algunas aproximaciones teóricas. Perfiles Educativos, núm. 87.

Tamayo, VA (2006). “El movimiento pedagógico en Colombia (un encuentro de los maestros con la pedagogía)". En: Revista HISTEDBR On-line, 24:102-113, diciembre - ISSN: 1676-2584 p.102.

Zemelman, H (1997). Sujetos y subjetividades en la construcción metodológica. En: Emma León y Hugo Zemelman. Subjetividad: umbrales del pensamiento social, pp. 21-35. Anthropos. México. 